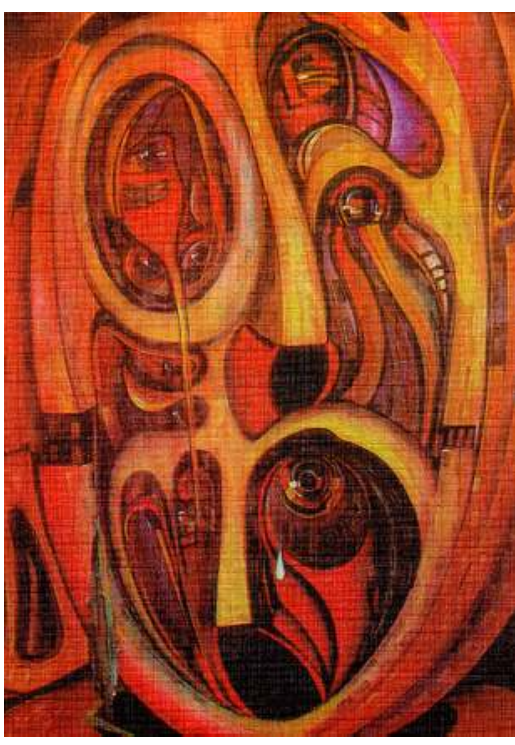

Peter. Z. Yemetz (Ukraine): SCREAM OF PRIPYAT CITY, $1987(08,08$, ard

\title{
ATOMIC NEUROPSYCHIATRY - A NEW CHALLENGE OF THE 215T CENTURY
}

\author{
Konstantin Loganovsky \\ State Institution «National Research Center for Radiation Medicine of National Academy of Medical Sciences of \\ Ukraine», 53 llyenko [Melnykov] Street, Kyiv, 04050, Ukraine, loganovsky@windowslive.com
}

Background: Operation and development of nuclear peaceful and military technologies, medical radiation exposure (including interventional radiology lab staff), perspective long-term cosmic flights, potential radiological terroristic attacks ("dirty bomb") could lead to occupational and/or emergency overexposure to ionizing radiation and significant stress that may seriously affect mental health and behaviour.

Goal: To assess the current state of art and future prospects concerning the effects of ionising radiation exposure to the human brain, cognitive functioning, behaviour and mental health.

Materials and Methods: Analysis of the available data on radiocerebral effects in interaction with the Chornobyl neuropsychiatric legacy.

Results: It is axiomatic that the developing brain is extremely radiosensitive. At present there are new evidences about the radiosensitivity of the mature brain, mainly due to continuous hippocampal neurogenesis in the adult brain; neuronal apoptosis; changes in gene expression, neurosignaling, neurotrophic factors; inflammatory and autoimmune responses, etc. There is the international consensus that long-term mental health effects are the key medical and social burden of the Chornobyl catastrophe, and include: 1) stressrelated disorders; 2) effects in the developing brain; 3) organic brain damage in highly exposed clean-up workers ("liquidators"), and 4) suicides. The stress and exposure to radiation together with highest radiation risks perception are characteristic risk factors at any radiation emergency. There are consequent data on radiation risks for cardiovascular/cerebrovascular diseases in Abomb, radiation accidents in Southern Ural and Chornobyl survivors and nuclear workers, as well as for organic psychotic and nonpsychotic mental disorders in Chornobyl liquidators.
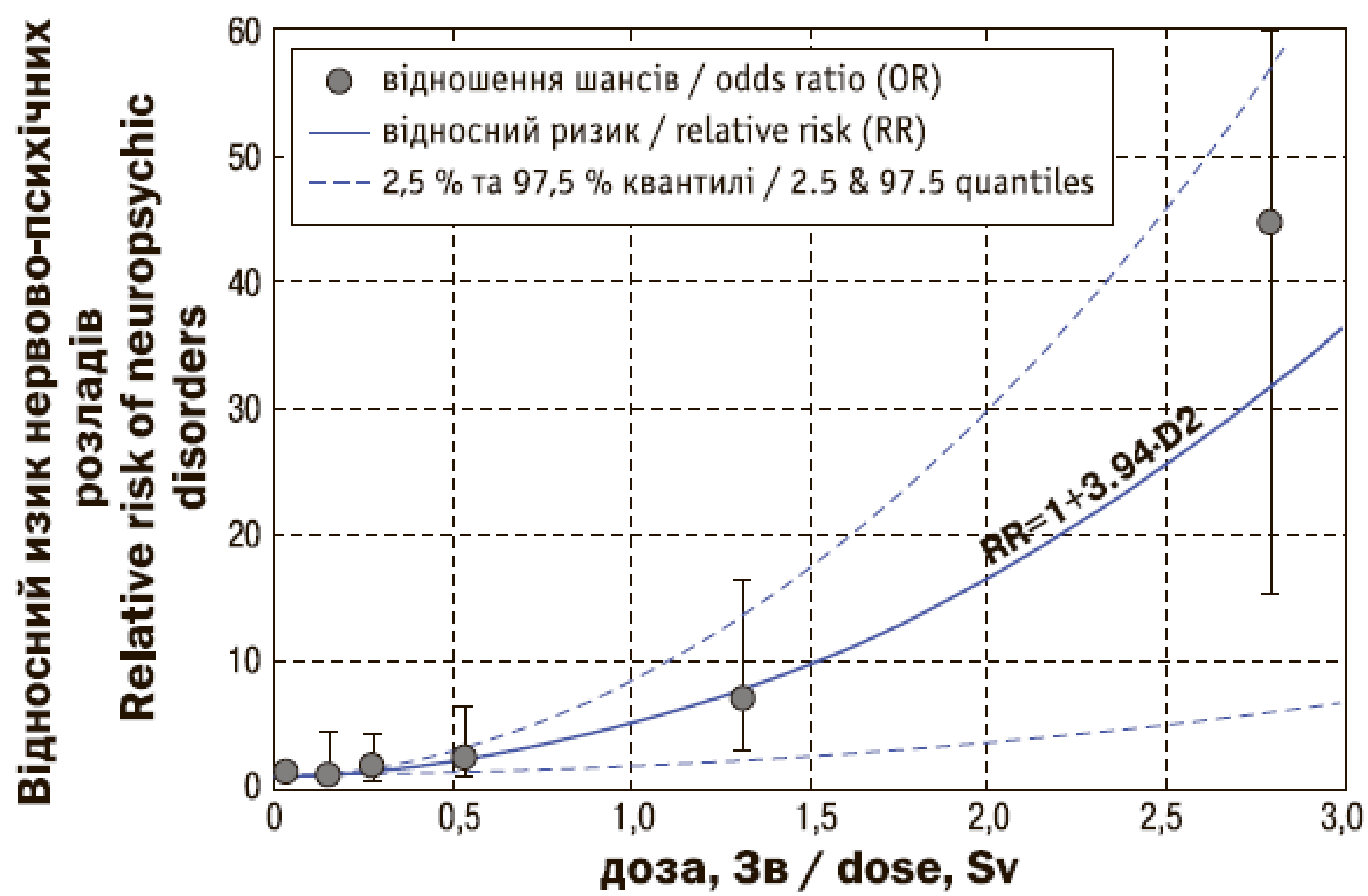

Dose-effect dependence on neuropsychiatric disorders in liquidators
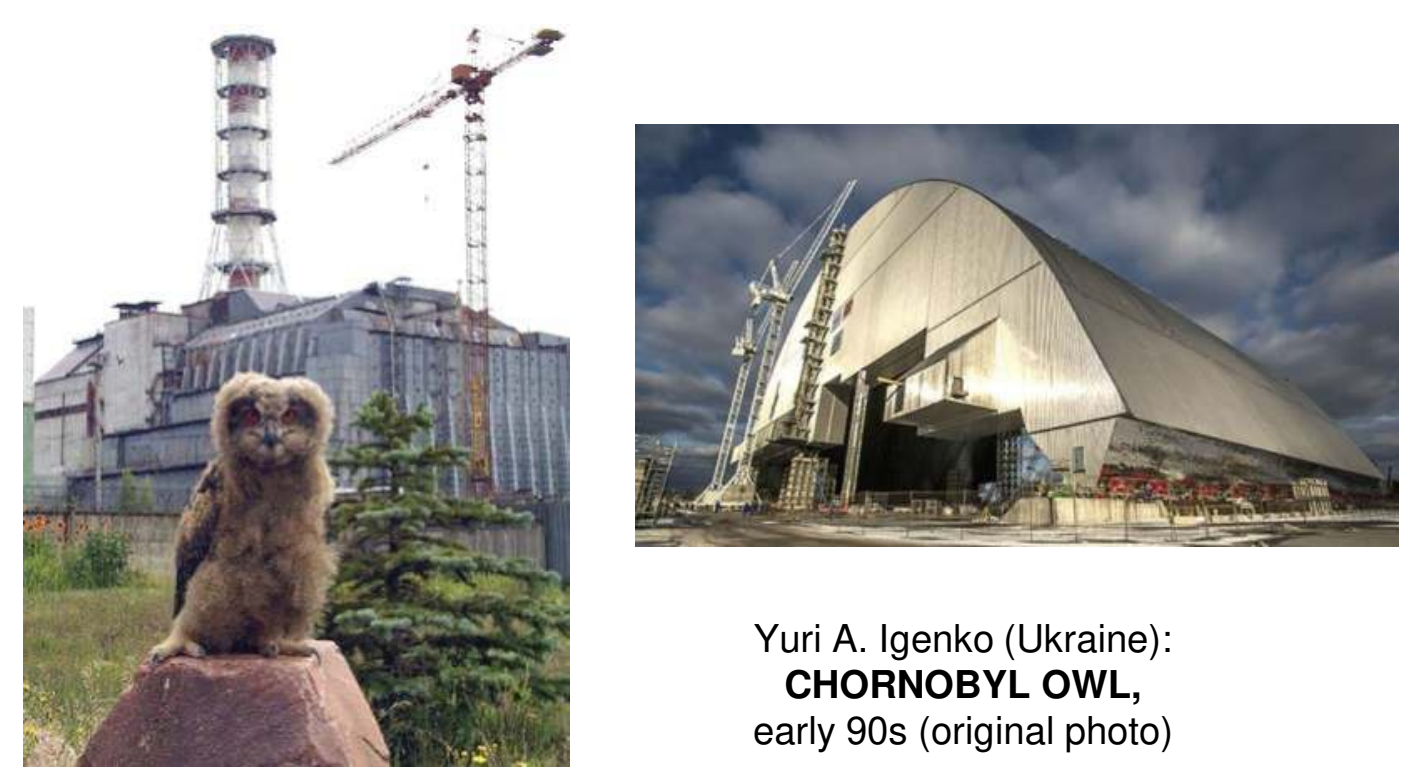

Yuri A. Igenko (Ukraine): CHORNOBYL OWL, early 90 s (original photo)

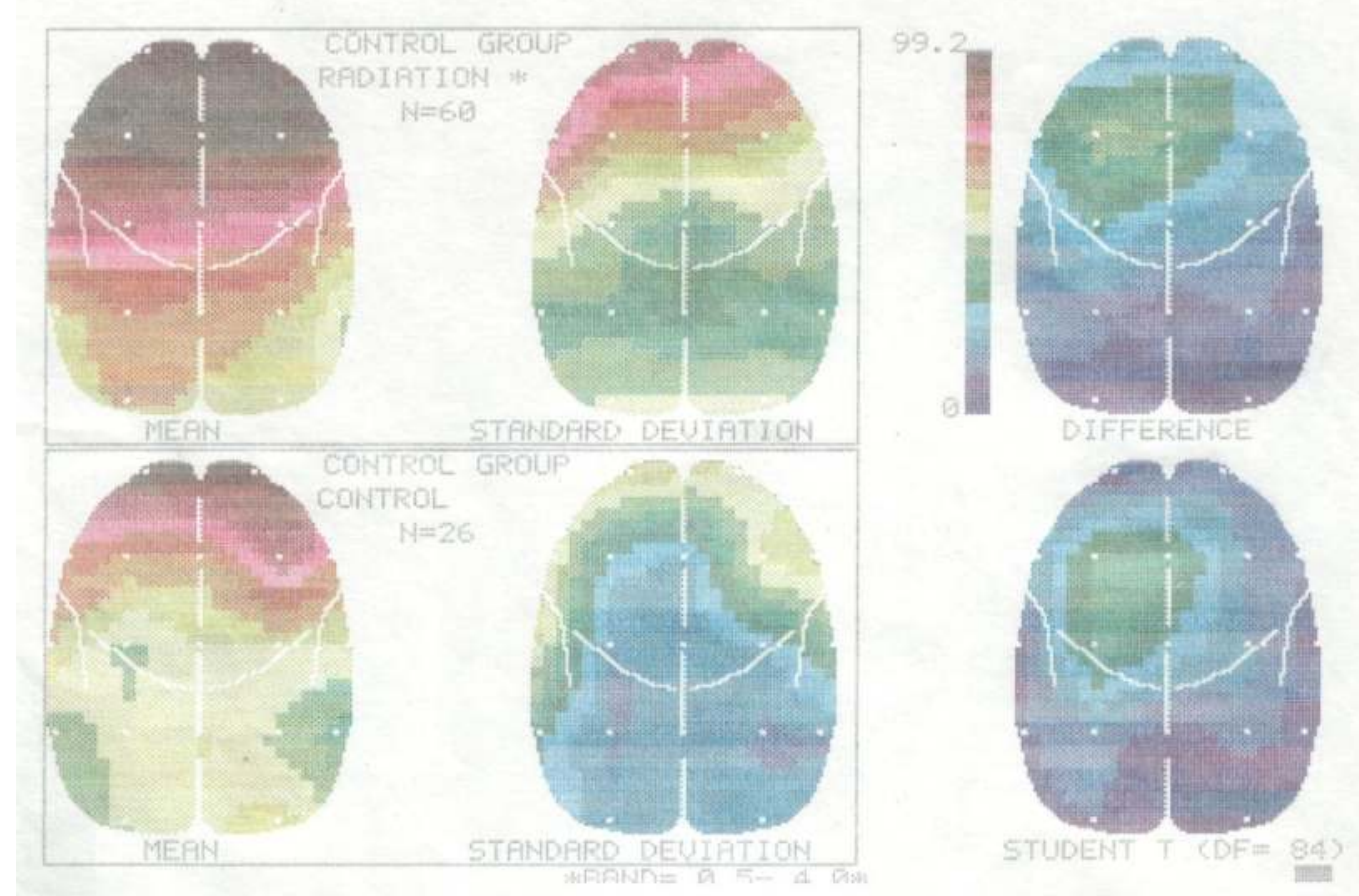

The first Brain Mapping Differences between the Radiation Exposure (Clean-up Workers, upper) and Stress (Afghanistan War Veterans, lower) (Noshchenko \& Loganovsky, 1991) Delta-power lateralization to the left fronto-temporal area

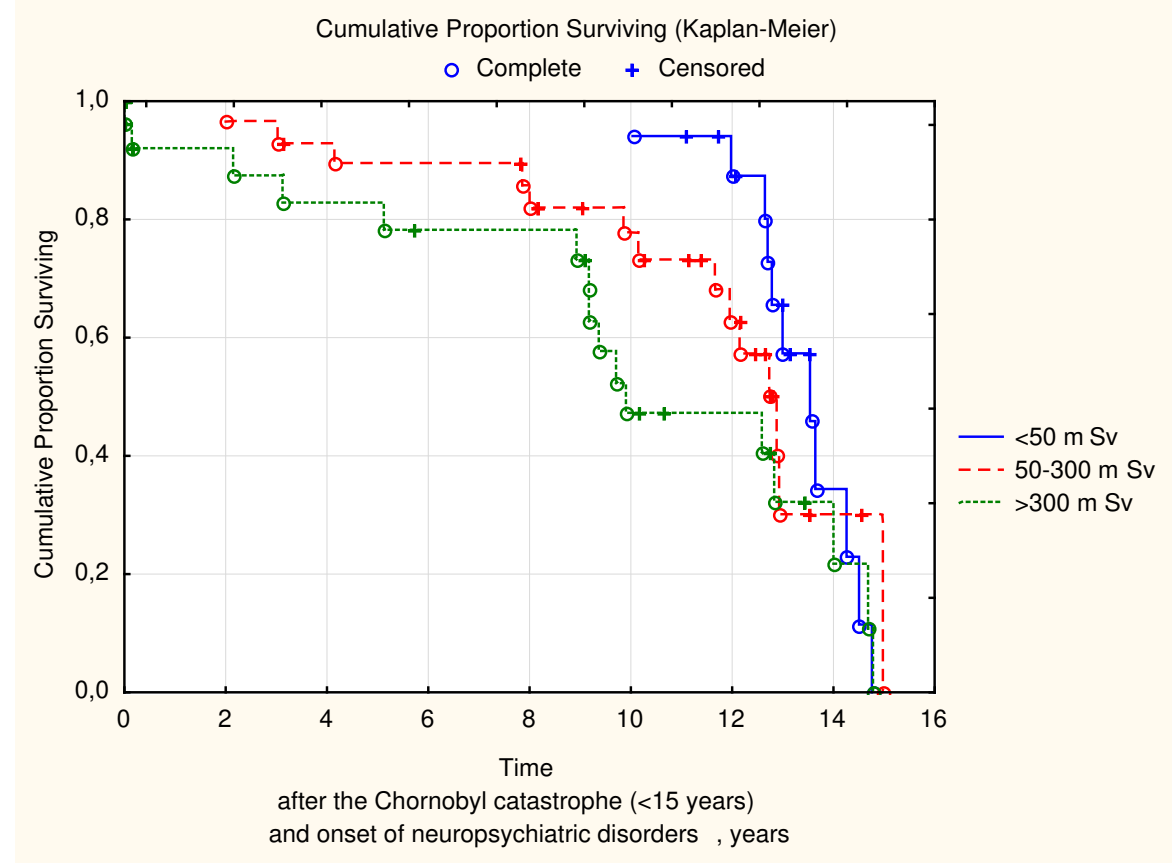

Survival curves (Kaplan \& Meier) for neuropsychiatric pathology onset after the Chornobyl catastrophe Comparison of liquidators exposed to different radiation doses during the first 15 years after the Chornobyl catastrophe $\left(\chi^{2}=8.74, P=0.01\right)$

Conclusions: The new direction in psychiatric research and practice - atomic neuropsyhiatry is proposed aiming to develop innovative radiocerebral biomarkers and protectors; prevention, countermeasures and mitigation of potential mental disorders associated with radiation exposure 